\title{
A view from the bodies corporate. 4. Boots Wellbeing Services
}

\section{F. Stuart-Wilson}

\begin{abstract}
To say I visit Christopher Potts at his office is something of an understatement. The Head office site of Boots the Chemists, of which Boots Dentalcare is part, is the size of a small town on the outskirts of Nottingham. Simply visiting gives one an impression of the sheer scale of Boots' operations in the UK - and why it is in some ways quite different from the other bodies corporate that I visit.
\end{abstract}

Boots' dental operation is one part of a very large business, and now itself forms part of Boots Wellbeing Services, which covers a range of services connected with health and beauty around the country. The Boots Dentalcare Board comprises three people and reports to the main Board of Boots the Chemists, as Chris Potts explains to me during the course of our interview.

Sitting in a meeting area in a large, airy modern atrium, I meet Chris Potts, who could be described as having a history of

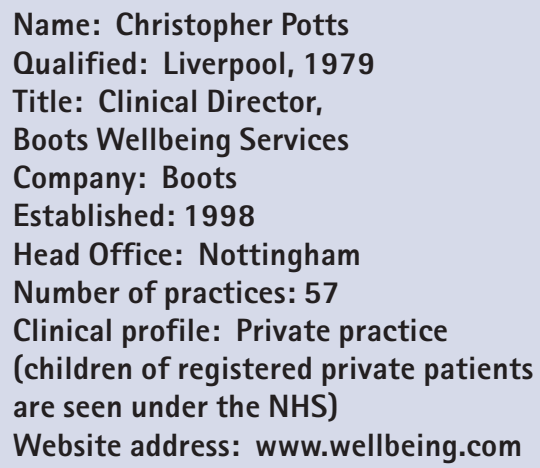

being in the right place at the right time. This would be unfair to him, however, if one did not also mention that he could also be described as actively taking advantage of opportunities that have presented themselves. He outlines his route to company director to me. 'I was an associate in Manchester for over 3 years, then in 1983, I set up a squat in south Manchester. The next year I set up another squat - both NHS practices. I stayed in the NHS until 1994. Then I realised I had learned to be a fast dentist. I wanted to be a good dentist.' Chris Potts looked around for his next steps and 'I saw the BUPA capitation scheme pilot being promoted and got involved when they came to Manchester. I was one of the first dentists to get accredited.'

By 1995 he was the BUPA Regional Dental Adviser in the north west, and added the role of chairman of dental focus groups in the north and membership of the BUPA advisory panel to his list of achievements. He is self-deprecating about this. 'They rolled me out doing 'Hallelujah I've been saved' meetings around the country, having been thrown in at the deep end the first time.' He had been asked to answer some questions at a meeting and was

\section{'I've got the most exciting} job in dentistry in the UK.'

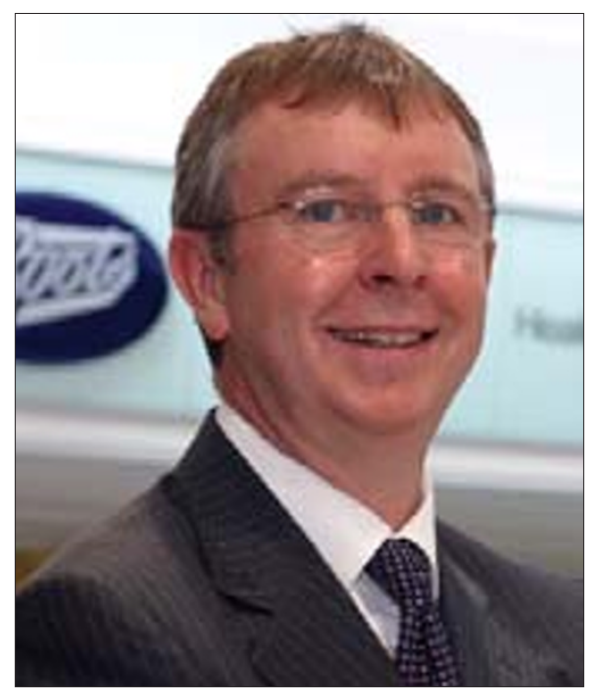

Chris Potts 
shocked to be introduced as the speaker; his performance at that meeting was good enough for him to become BUPA's 'roving ambassador'.

That link with BUPA was to prove critical to his career. 'The BUPA MD, Jonathan Walsh went to set up an insurance services company for Boots.'

By early 1998 Chris Potts's practice was '95\% private with a third of patients under capitation. I was happy.' However, Chris was clearly still seeking new challenges because he wrote to Jonathan Walsh about

\section{'Setting up a Boots}

practice is a massive

financial undertaking. A

practice costs half a

$$
\text { million pounds to fit out }
$$

plus start-up costs.'

'Boots entering dentistry. The week my letter arrived, Peter Smith had been told to look at dentistry.' He explains that Boots' business development 'would look at new ideas. I started doing a day a week doing a feasibility study of dentistry named "Project White",

Chris became involved in the acquisition of Wilsons (the body corporate) on the 8th September 1998, and became a dental director. 'Alan Brook, Dean at the School of Clinical Dentistry, Sheffield University was a non-executive Director. I spent a day a week doing this and the rest of the time running my own practice. I became more involved in Boots and we set up a pilot of 6 practices. The first Boots practice opened on 10th May 1999.'
By August 1999, all six pilots had been set up. By Chris Potts's own admission it was very swift. He then explains the breadth of his involvement at this stage. 'It was a very fast set up. I got involved in developing systems for recruitment, equipment, marketing, treatments, software.' (Software of Excellence won the contract to supply Boots.) 'All systems are attached to Boots tills in our 1,400 stores, so we needed a robust system.'

'The pilots were located along the M4 corridor and up a bit. They went well and feedback was positive. We received permission from the main Board to roll out another 50, and at that point I decided to join the business full-time.' It is difficult to remember that at this stage he had been working with the company for only one day a week. He is however keen to impress upon me that 'I wasn't unhappy before - I wasn't looking for a way out.' He eventually sold his practice in 2001, but clearly has no regrets. 'I've got the most exciting job in dentistry in the UK.'

As he goes on to describe how the next stage of Boots Dentalcare rolled out, it is clear that the scale of resource that Boots can provide makes this undertaking and their approach very different from those I have already seen. 'Setting up a Boots practice is a massive financial undertaking. A practice costs half a million pounds to fit out plus start-up costs. We staff them very well. On the day we open it looks like a mature practice.' It sounds as if the process is very well defined, and Boots' attention to process comes up again later in our conversation.

'We looked at how we would implement the roll out and planned through - we have just got to 57 practices - the Nottingham practice is the $57 \mathrm{th}$. We were still at 6 in

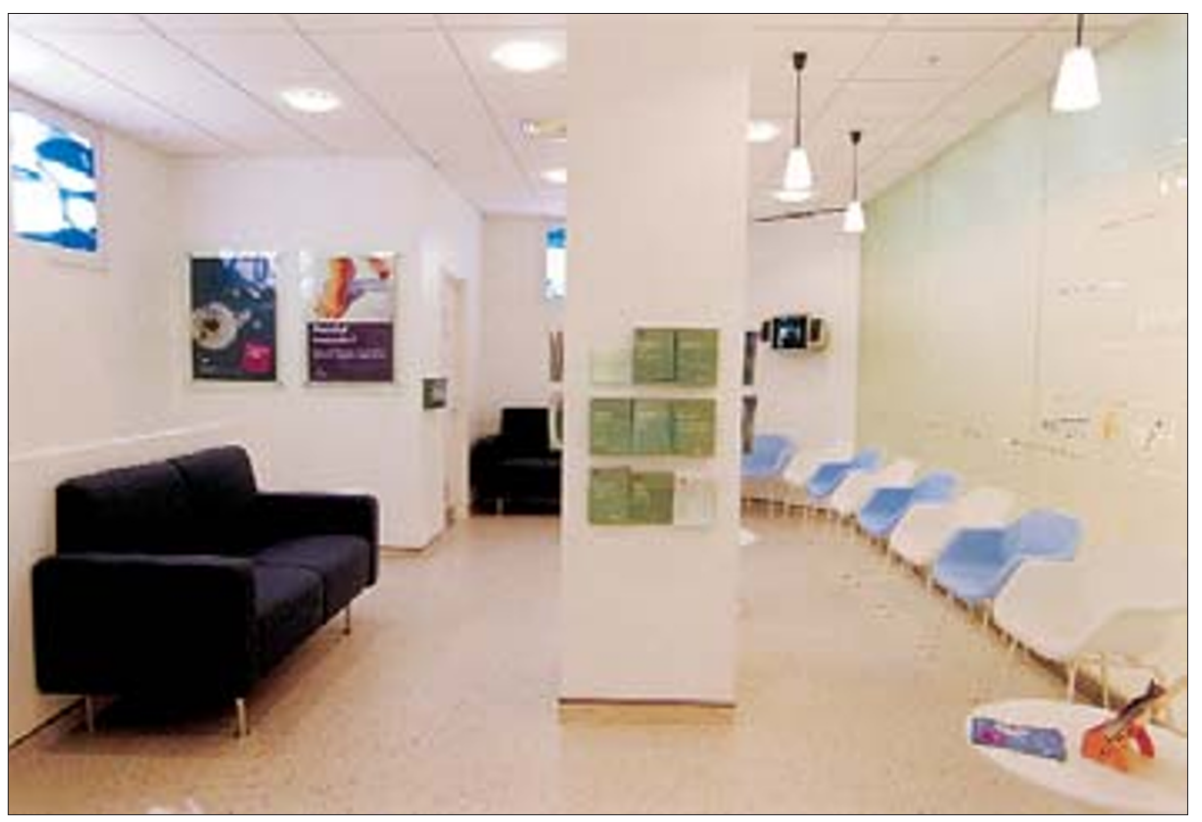

The reception area at one of the Boots Dentalcare practices
'We drew on our experience

\section{and resources from our}

\section{optician business'}

August 2000, so that means we've set up 50 in two years.'

I am interested in his next comments that 'We drew on our experience and resources from our optician business. There is a wealth of experience around the business.' That wealth of experience includes that of the board members. 'The other board members are Alan Brook, and Norman Usher. Norman Usher is the MD (he is also MD of Boots Opticians and Boots Wellbeing Services.) We are bringing lots of services together. We have a stronger voice with the main board and a stronger marketing presence.'

This last comment reminds me that in operational scale Boots Dentalcare is far smaller than its optical counterpart. There are around 300 Boots opticians practices.

'At the moment some of the dental practices are not in-store, they are stand alone. I think in-store is probably the way forward - we look at use of space and the return on square footage is very important.'

He quotes easily some facts and figures about Boots, using business language not often heard amongst dentists. "We can use the footfall that Boots has to resource dental practice. We have the second highest footfall in the UK after the Post Office.' Add to that the statistic that half the adult population shops at Boots every 4 weeks, and one begins to understand the scale within which Chris Potts is operating. As soon as I ask my next question I realise within that environment how ridiculous it sounds, and he smiles as he answers it. 'Competition? We don't really have competition. We're there to offer high quality aesthetic dentistry. We worry about that, not what other people are doing.'

I ask which changes in dentistry he sees as most important. His answers are interesting. 'All changes are important. PCDs will be a very welcome change. The more people can do, the better. It's good that people will have a career path and progression. Boots will be evaluating the legislative changes, but we must remember that the population is used to a dentist doing things, so it'll be an educative process for patients.' The word evaluation crops up several times. By way of explanation, Chris says 'I would hate to do something that was a knee-jerk reaction. We might do a pilot for example, with hygienists taking on additional duties.'

I ask about the registration of nurses, and an openness about making changes in the light of experience emerges - and is 

going to use qualified staff. But it hasn't always been possible. There is a real shortage in the M4 corridor. We will take nurse students but they have to take the dental nursing qualification usually through the NVQ route.'

Another change that Boots made was changing their application procedure. 'We dumped the pilot application form - it was too daunting. It can be a culture shock for dentists coming to work for Boots. There is a half-day selection centre following a telephone conversation and

\section{'Part of my role is to}

\section{protect the Boots brand as}

\section{well as protecting and}

looking after patients.

\section{Patients have particular}

\section{expectations because we}

\section{are Boots.'}

the submission of a CV. If those are $\mathrm{OK}$ they are invited to the half-day selection centre.' Over $50 \%$ of applicants go on to a selection centre, which comprises 'a clinical interview, competency tests, an interview testing softer skills, forms testing values, a group exercise discussing scenarios, and a presentation on Boots Dentalcare. returned to several times. 'We were always

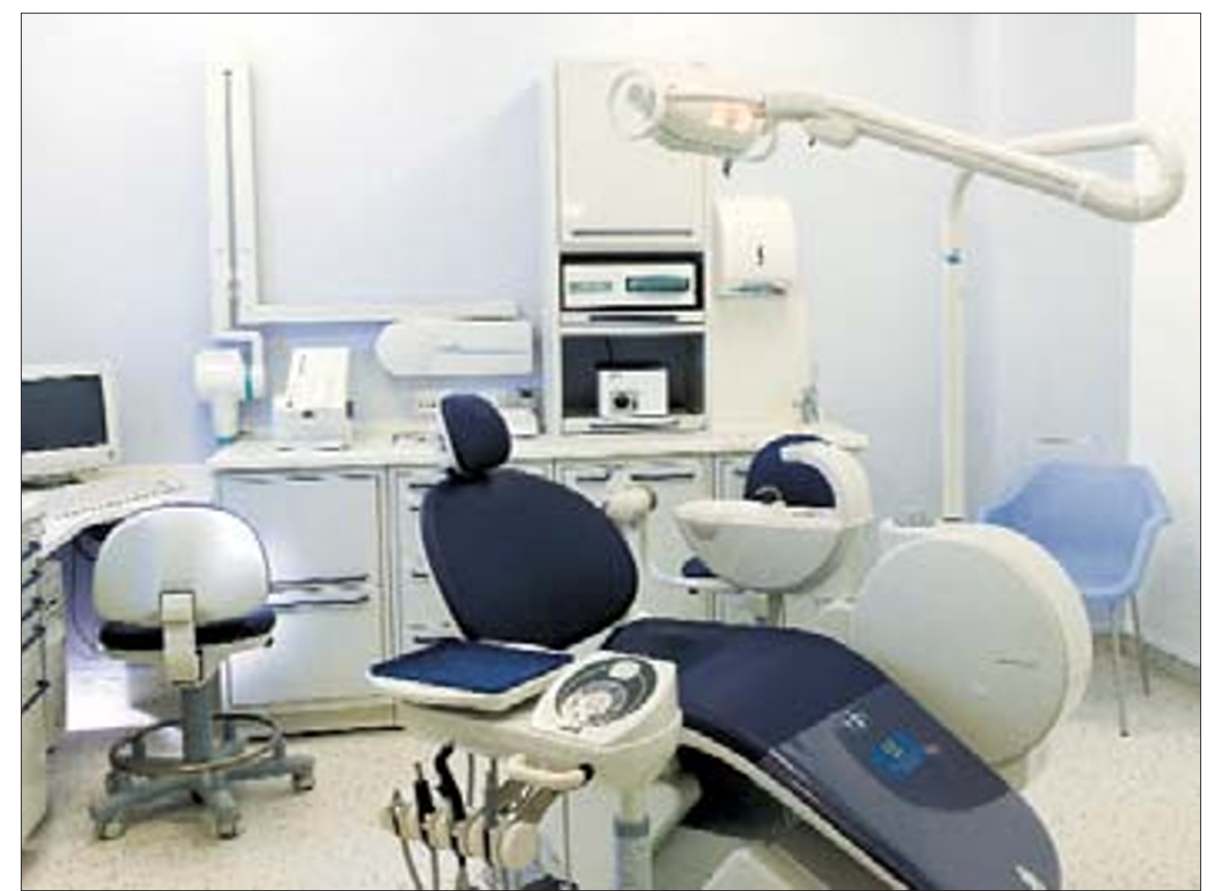

A Boots Dentalcare treatment room
We return to changes in dentistry, which Chris Potts now links with recruitment. Although NHS income accounts for what Chris describes as a tiny percentage of their income he says that 'the new pilots in the NHS can only affect us in a positive way. A core service would mean recruitment would be easier for us. I am not convinced that there are massive changes on the cards, and I think that there is a question mark over access centres.

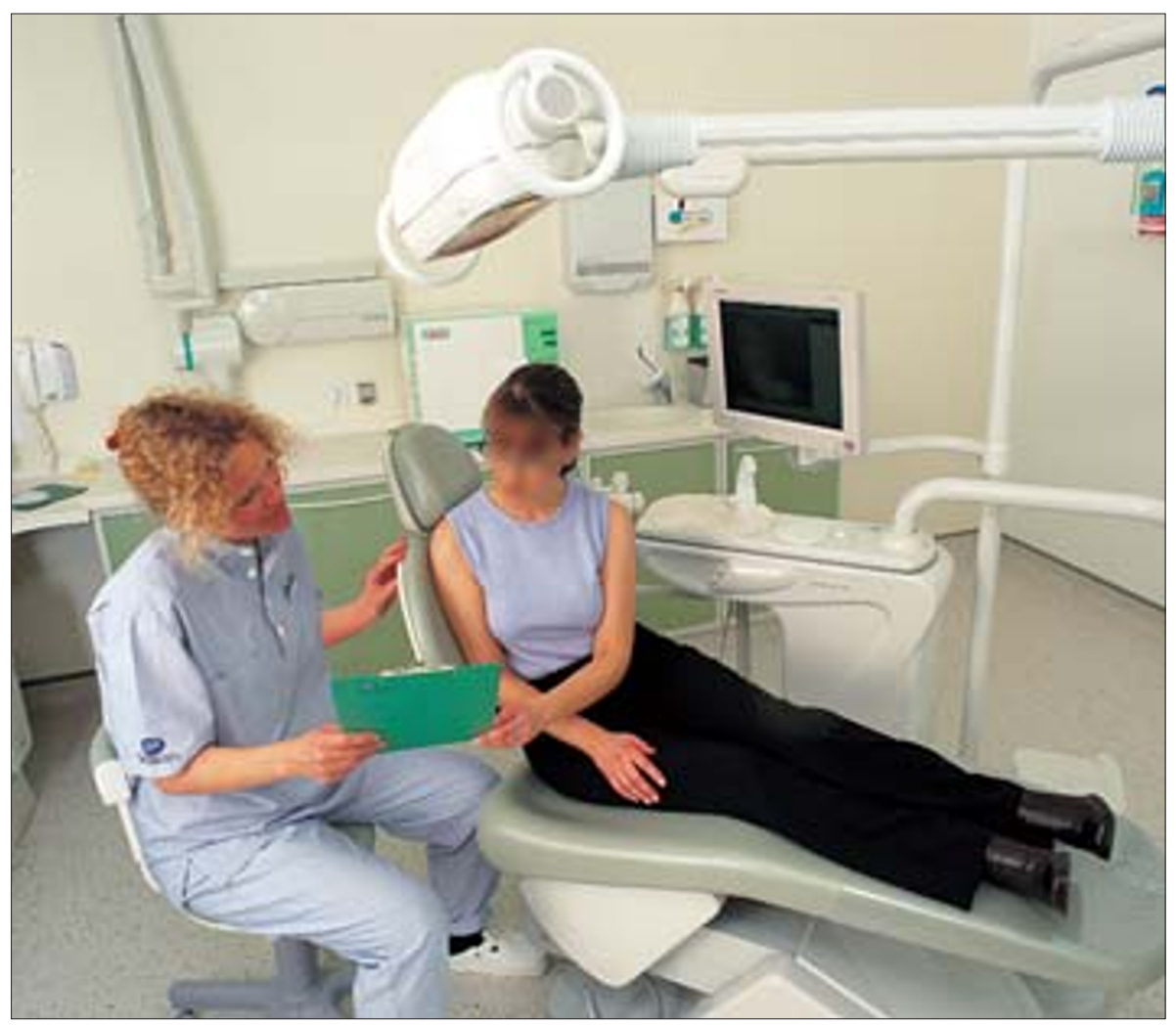

A patient discussing treatment options in a Boots Dentalcare treatment room
'I always thought that the limit on bodies corporate would be lifted. In 1998 we reckoned if we got four years that would be good. I don't see that there will be a rush to set up more bodies corporate. The big players would have come in by now.' So far as the regulation of bodies corporate is concerned, 'If a dental body corporate strays, they can remove the bodies corporate licence. Because of that, the GDC will not over-react. The sanction is all or nothing. The Optician's Act is a lot fairer and more equitable - there is a scale of sanction. I 'now you can't pick up a
glossy magazine without it mentioning dentistry.'

think there should be a level playing field. Bodies corporate should be treated the same as individuals. That doesn't mean that sanctions should be diluted, but that's highly unlikely.'

Talk of sanctions brings us to the area of quality assurance. 'The Boots QA programme took 3 years to develop to ensure that we offer the quality of dentistry we say we do. If the regulations change we are well-placed to deal with them.' Chris Potts considers that for him, quality assurance has a double edge, which leads us into a discussion on patient expectations which has formed part of my interviews with all of the bodies corporate. 'Part of my role is to protect the Boots brand as well as protecting and looking after patients. Patients have particular expectations because we are Boots.'

'Over the next five years patient expectations will almost certainly get higher. 
Five years ago they were lower; now you can’t pick up a glossy magazine without it mentioning dentistry. More law firms are willing to come on board if something goes wrong. Patient expectations feel higher for us because they trust us and expect us to be good. To give them a 'wow' you need to be really good.'

I ask if this level of expectation concerns him. By this stage I am not surprised at the answer. 'Does it concern me? No. We're nicely-placed and I love a challenge.'

I ask him to look ahead five years. His answers are different from some I have heard in these interviews. 'Five years is not a long time. I think there will still be a GDS slowly creeping towards a core service. In financial terms there will be more private dentistry than NHS.'

'Patients will want to keep their teeth longer. There will be higher aesthetic demands, as in the US. I am not sure that we will have made a major leap towards more private dentistry but it will be considerable.'

He goes on further to explain his answers.

'We have patients who haven't been to the dentist for several years - one patient hadn't been for 57 years. We are picking up patients from the 'missing 50\%.'

'I wanted to get involved in something that would open the market, not put colleagues out of work. The market will grow, and the private spend will go up at a reasonable rate. We will pick up some of that market growth and so will my colleagues. Five years won't get us to where the opticians are now. Five big players account for $50 \%$ of the optics market at the moment.'

\section{'If I went to university again I would still do dentistry. It's a fantastic profession, there's so much you can do with it.'}

He echoes the comments of other dental directors. 'There will be consolidation in the bodies corporate market but I think there will be some new entrants as well.'

'For Boots in 1990 the time was not right to go in. In 1998 it was right. As time goes on it looks better and better. Because of the way the NHS is funded, we couldn't have made money. As the private market and the demand for cosmetic dentistry increases, it looks better for us and fits in with what customers want.'

He believes they are giving customers what they want, and that is inextricably linked with consistency. 'We are getting 1,500 new private patients a week (around 30 a practice). In the early days we were being asked for second opinions by some patients, but now 4 out of 5 that come to us take up their treatment plans. We bought a lab and have a roster of labs to ensure quality.' Quality again. 'The consistency of experience is important for patients. Proper protocols, similar labs - that's one of the ways we will succeed in ensuring that consistency.

'Our QA has taken a long time to develop and fine-tune. We have a five-day CPD programme in place. Everything is geared around quality. We use specialists to deliv- er hands-on clinical training. We have training facilities in Oxford Street, London and in Oldham.'

He is, however, realistic. 'We don't get everything right all of the time, but we get most things right and are getting more right as we go along. We're growing with the business and I want us to become the employer of choice. We have 10 centres of excellence around the UK with 35 specialists and are now taking external referrals.'

He goes on to talk about the importance of people. 'Overall we have a fantastic team who want to make this a success. There's a strong emphasis on training. We have 190 dentists, more than 90 hygienists, over 320 nurses and 35 specialists - it's a big Christmas party! We can build a practice in 8 weeks but it can take 7 months to staff a practice. We don't cut corners when taking on staff. Team membership is very important. It's essential to everyone that they get on well. We have a four week induction for a new practice for the whole team.'

For Chris Potts his career has been a success, and his enthusiasm for Boots Dentalcare is very apparent. This is the only interview that I have conducted where the dental director does not mention any other corporate by name, and sitting in the vast Boots edifice I can understand why. But Chris's last comments seem to demonstrate that his commitment is not just to Boots but to dentistry. 'If I went to university again I would still do dentistry. It's a fantastic profession, there's so much you can do with it.' And with that the man with the 'most exciting job in dentistry' bids me goodbye and disappears into the Boots empire. 